\title{
Literary Creativity from the Perspective of Cultural and Creative Industries
}

\author{
Ni-na ZHANG \\ College of Arts, Yu Lin University \\ Yu Lin 719000, China
}

\begin{abstract}
With the rapid development of science and technology and consumption levels rising, the cultural and creative industries have increased rapidly. In the new era of the development of cultural industries which is characterized by originality on the basis of the core element of creation, creative literature is considered to be an important support for the cultural and creative industries. And literature, as the soul of cultural industries, is inevitable to integrate with economic, scientific and culture. The author agrees that in the background of development of cultural and creative industry, it is imperative to pay more attention to the marriage of literature and film, so as to promote the development of cultural and creative industries.
\end{abstract}

\section{Keywords—Component; Formatting; Style; Styling; Insert}

\section{CHARACTERS; THE SOUL OF CULTURAL CREATIVE INDUSTRY}

With the passing of the era of capital and the advent of creative era, cultural creative industries have increasingly highlighted the value of "creativity" or "creativity", literature industry has become "a Chao Yang branch with great potential for development, not only to spread the social value of positive thinking, but also exposed the broad prospects of cultural consumption. [1]" In addition, literature is recognized as the main way to cultivate and train the ability of "cultural creativity". The content of literary creation and the creative ability consciousness of literary activities are the basic form and skills of cultural and creative industries which rely on individual to develop and marketing intellectual property through technological innovation and industrialization technological innovation. From then on, the soul of creative industry comes from literature [2]. Moreover, the basic quality of literature determines the creative talents of a nation, because the creative creativity of people is the ingenious fusion of scientific rational thinking and irrational inspiration, and it is difficult to obtain through other disciplines system knowledge, only from artistic accomplishment. in today's new era of cultural industry development, creativity has undoubtedly become the most important feature and the most significant symbol, As the soul of cultural and creative industry, literature is inextricably integrated with economy, culture and technology, at the same time, the operation of cultural industrialization will inevitably require literature to " human creative thinking and cultural creation as the basis, to promote the optimization and upgrading of cultural industry through literary creativity."

\section{LITERARY CREATIVITY}

What is the literary creation? Professor Tian Chuanliu, a professor of cultural and creative research, believes in "the literary creativity of the creative age": Literary creation, that is to use creative thinking, to engage in literary activities and creation in a pluralistic and systematic way, to strengthen the literary meaning and its role, and to enhance its cultural value and economic value. [3]" Therefore, the essence and connotation of literary creativity can be seen, the literary ideas, its fundamental purpose is to enhance the literature cultural value and economic value, its primary task is to strengthen the literary works through space-time and expressive force, its important mission is to explore human inner emotional world and aesthetic ideal, the literary communion with other art in shape and quality has become an important form of literary creation, the combination of literature and film, in the new era of cultural creativity, the interactive adaptation of their combination is both an important activity of literary creation and an important content of literary creation.

\section{WIN-WIN: THE COMBINATION OF LITERATURE AND FILM}

Under the background of the development of cultural and creative industries, "literature and television film have been married, the connection and interaction between them is actually a win-Nwin good thing. [4]" For literary writers, film and television provides a broader and more accessible marketing communication platform for literary creation. As the starting point of the value chain of cultural industry, literary creativity provides scripts and planning resources for film and television through $\mathrm{R} \& \mathrm{D}$ and creativity, and continuously generates fresh blood and life factors for it.

\section{A. Promoting cultural and economic value of literature in an all-round way}

In the era of cultural creativity, the artistic and commercial of literary works have been fully excavated and developed, outstanding performance is the combination of literature and film and television

the image, dissemination, timeliness, visual, universality and other characteristics of the film culture, also more effectively show the human ideology and aesthetic concepts, reflecting a nation's humanistic feelings and cultural integrity, it is greatly enhancing the cultural value of the literary performance At the same time, the commodity, popularity, entertainment and popularity of screen literature liberated the lonely situation of the high places of traditional elegant 
literature, to make literary works enter the market of cultural consumption in the way of a more commodity product form close to the human life, and enter the market orbit of production, circulation and consumption, this requires that it pays more attention to economic and economic value while paying close attention to social benefits, take the movie adaptation of a fairy tale, the creators of film and television are particularly good at seizing the literary works of different regions, nationalities and cultures, which are used to decode and encode the western unique cultural values and ideas of the United States, and create a movie and TV legend that wins the box office and the word - of - mouth. for example, according to statistics, there are thousands of films and TV works drawn from German fairy tales from Green, film creators use this fairy tale structure and characters unconsciously or consciously to meet the cultural expectations of the world, even consciously deviate, reverse and surpass this narrative tradition, it is still wrapped in a constant spiritual core in the strange narrative, from this, through the magic wand of film and television, the traditional literary resources have realized the "Cinderella" style of gorgeous turning and transformation, and it is also realized the widespread dissemination of cultural values, at the same time, the traditional and simple cultural concept and ideological value of human beings to have a universal dimension of the dimensions. The combination of literature and film strengthens the consumption of culture, and the process of repeated production of pure literary works through film and television creation becomes a popular cultural product in line with the consumption interest and consumption habits of the masses, ass culture as a " pursuit of economic benefits" cultural form, market - oriented, with the audience as god, while focusing on social benefits, it more emphasis on " economic benefits" in addition, the creators maximize their economic value by studying and designing the production and marketing of literary works, for example, Harry J.K, a series of literary works created by British female writer Rowling Potter, successfully realized the qualitative flying from the initial literary creation to the later literary creation, it Gradually created a book sales as the center, set language translation, film and television adaptation, cultural tourism, derivative product development as one of the multi-linkage marketing new era, in a sense, " Harry Potter" has transcended purely literary meaning with its industrial significance, in this regard, the famous American economist Romer believes that " creativity is the driving force to promote the economic growth of a country." therefore, as an important content of literary creativity, the combination of screen literary reflects the human thinking to create the contemporary demand for development, It reflects the seamless and efficient docking of literary production and literary consumption under the market economy [5].

\section{B. Strengthen the expressive force of literature and the space- time force of penetration}

The core of literary creativity lies in "the creation and pursuit of the literary spirit of human consciousness, including the pursuit of literary image, implication and artistic conception. ". obviously, the perfect combination of literature and film, not only brings powerful audio-visual impact and strong audiovisual aesthetic pleasure, but also greatly expands the literary field of view, and strengthens the tension and expressiveness of the static text, by adding rich connotations and profound connotations, it focuses on humanistic care and human nature, goodness, beauty and other universal values of the image presentation, In particular, the cross-cultural film adaptation of literary works promotes the integration of literature and other human culture, it makes film and television creation beyond the gap between different language and cultural cognition, showing the aesthetic feeling through time and space, enduring, long and new, so it can be a timeless classic product for all mankind. The cross-cultural film adaptation of many literary works focuses on the double coding of cultural locality and cultural internationalization, which not only keeps the local culture, but also has the richness of the world's pluralistic culture. The strong expression of the film as an " international language and the language of all human language iv, it can easily eliminate" cultural discount iv, breaking through the shackles of its own regional culture and other cultural identity, easily become the universal acceptance of cultural products. The language art of "translation" of sound and picture, light and color image, dynamic and static, fast and slow, it not only can make it easier for the audience to get deep emotions and rich aesthetic feeling, but also can make people more profound understanding and rational thinking. taking the American Hollywood adaptation of the Chinese literary works "Mu Lan ci", "Mu Lan I" and "Mu lan II" as an example, the film breaks through the single character image in literary works and the direct literary narrative mode, and displays the individualistic spirit of " pursuing personal value and achieving individual struggle" with dramatic contradiction conflict in film and television narration. It not only shows the American traditional cultural values, but also caters to the value pursuit of the universal popularity in the world. therefore, the film adaptation of literary works through the double presentation of text and image, with the help of a very space-time penetration of the universal cultural values, it is easy to realize the diachronic integration and the extension of space, and give the thousands of years of history and traditional ideas to be independent, new, eternal and through the vitality of time and space.

\section{Deeply inquiry into the human inner emotional world and aesthetic ideal}

Film and television is the recreation of literature, and the literary film and television creativity can explore the human emotional world and aesthetic ideal from multiple latitudes, the adaptation of excellent literary works, through the transformation of language art form to the image art form, it is the literary creation and Again of literary creativity based on the recognition of the present age. to a certain extent, it can follow the original spirit and artistic spirits and seek the cause and start the audience emotional resonance and ideological implication connotation of shock, which can more deeply explore the social ideal and aesthetic pursuit of human being From literary works to film and television art creation, it can not only clearly express the aesthetic consciousness of the creator, but also fully meet the aesthetic direction of the audience. It is the activity of aesthetic creation and the realization of the spiritual value of aesthetics, Literary works can make full use of the characteristics and advantages of the national language and characters, but as a special feature of " international language and all human language ", it is recognized that the film, as a" international language and 
human language ", it can make the emotional world and aesthetic pursuit of the film more widely spread across the nation, across regions and across cultures. the creation of film and television throughout the United States in recent years, from the fairy tale for the legendary Hollywood film adaptation of Green fairy tale meet the eye everywhere, such as the "Little Red Riding Hood" of the animated film "hoodwinked", boldly break the inherent mode of traditional cognitive thinking, the multi angle, all-round, subversive creation. Give people conform to the cultural spirit of modern society's personality, spiritual core conveys modern spirit with contemporary society, times and explore the modern human emotion and cultural beliefs, shaping a cultural trend with contemporary spirit, therefore, the emotional world and aesthetic ideal of human beings realize the interactive communion through static black and white writing and dynamic color images, which make readers and viewers gain deeper level of thinking and aesthetic thinking, conform to the intense pursuit of realistic psychology and the pleasure of daily life as a result of the principle of popular culture pleasure, and also reiterate the positive influence of the film and TV culture guiding the care and expression of humanistic value and the construction of modern humanistic spirit.

\section{Extensive development of literature and other artistic forms and quality blend}

The influence of literature on art is significant and far reaching. whether it can absorb nutrition from other art forms has become a decisive factor for any kind of art to gain the power of life, in today's creative era of interaction, dialogue and integration of many art forms, the reference and integration of various other artistic elements should be an important task of literary creativity, literature with its position in the center of the long-term dominant or artistic style, based on a wide range of audience and the creation of the creative group, with its unique language expression and profound insights, it is continue to show the charm of free from vulgarity and exuberant vitality of across space and time, literature and music, together with the perfect fusion of poetry and song, let the literature with " song" and " singing ", with" singing " and" read ", become a " read song ", is a creative wisdom, more is a kind of literary creativity. Literature and art, such as cartoons, illustrations and comics, etc., invade the characters not only in the eyes, but also in the imagination, not only in the presence of space, but also in the time course, with the combination of light and light to enrich the literary imagination, and increase the sense of beauty in literature. Especially the combination of literature and film, not only greatly enriches and expands the expression field and the living space of literature, but also creates a cross - meaning branch art style and artistic creation, which is full of vitality, and creates the crystallization of the combination of literature and art, first of all, the integration of literature and film not only excavates the ideological connotation of film and television culture, strengthens the ideological strength of cultural communication, but also expands the scope of literary works, Secondly, the integration and absorption of the basic language and expression elements of the diversified artistic style give a steady stream of vitality and vitality to literary creativity. Again, the depth fusion of literature and numerous artistic styles, has generated a new artistic style and works filled with fresh vitality, such as film literature, television literature, drama literature, music literature and so on, forming the correspondence, interaction and hybridity of literature and art, in a word, film and television can combine the characteristics of literature and art into its own new quality by absorbing the characteristics of literature, and the profound implication thought is presented in the perspective of multi perspective art, which has already benefited from the second creation based on literature as female parent and literary works.

\section{CONCLUSION}

In the new era of cultural industry development with creativity and creativity as the core, literary creativity is recognized as "the core category of cultural creative industry, it is an important support point of cultural industry, and its construction of cultural soft power has a long - term mechanism. [6]" throughout the advanced developed countries and the United States, the strong literary creativity is the real foundation of its cultural industry, which is known as the power engine for the development of the whole cultural industry. Therefore, literary creativity in the perspective of cultural and creative industries requires us to focus closely on the existing literary thinking and creative ability to adapt to the development of creative era, how to adapt to the needs of cultural industry and the demand of market economy, how to continue to expand and fully activate the creative market at home and abroad, as well as the literary creative workers in the pursuit of spiritual pursuit and social responsibility, while exploring the literature market effect and reflecting the social welfare of literature, shoulder the historical responsibility of promoting the healthy development of creative industries and promoting the international competition of cultural and creative industries.

\section{ACKNOWLEDGMENT}

Literary creativity from the perspective of cultural and creative industries (2015CXY-11) supported by the Yu Lin Science and Technology Bureau.

\section{REFERENCES}

[1] Shang Guang. the development of literary industry in the perspective of cultural warehouse LJ industry: a case study of Yan Yan Geling's works industry development [j]. Journal of Fujian institute of administration: social science edition, 2013 (1): 15 - 18.

[2] John · Hartley.Creative industries reader[M].Beijing:tsinghua university press, 2007.

[3] Tian Chuanliu, literary creation of the creative age. Journal of Literature and Art, 2009 - 18 (3).

[4] Feng Lingrang literature has become the driving force of film and television development. Journal of Literature and Art, 2012-12, 11 (3).

[5] Han Baohua.The evolution nature of creative practice system in cultural and creative industries [j].Journal of Shanghai University of Finance and Economics,Vol.18 No.1 Finance and Economics Feb.2016

[6] Yin Jun. animation industry and promotion of cultural soft power countermeasures [j]. Journal of southwest university for nationalities: humanities and social sciences, 2012 (5): 155 - 158. 